\title{
Value-Added Tax and its Implication for the Provision of Private Health Services in Botswana
}

\section{Zein Kebonang}

Lecturer of Law, University of Botswana

\begin{abstract}
This paper examines the impact of Value Added Tax on the provision of private health care in Botswana and argues that government cannot succeed in the discharge of its social obligations unless the private sector is also taken on board. The introduction of Value Added Taxation has led to an over-whelming demand for and constraint on government health facilities and a decline in the number of patients seeking private health care service. The government's success in providing health facilities must be complimented by private sector participation and this can be achieved by providing certain incentives such as zero rating and exempting the provision of certain health care services.
\end{abstract}

JEL H23

\section{INTRODUCTION}

Botswana has recently introduced a Value Added Tax (VAT) ${ }^{1}$ to replace the Sales $\mathrm{Tax}^{2}$. VAT, unlike Sales $\mathrm{Tax}^{2}$, which was selective in its application, is a comprehensive tax. Absent any exemption, it taxes almost all goods and services.

Under current VAT legislation, the provision of health services has been brought under the Act. Under the $2^{\text {nd }}$ schedule of the VAT Act, public health facilities are exempt from VAT. Certain drugs (particularly HIV-AIDS related drugs) prescribed under schedules 1, 2 and 3 of the Drugs and Related Substance $\mathrm{Act}^{3}$ are also exempt. Private health facilities, however, do not benefit from the same exemption. Except for certain drugs, the Act provides for a uniform tax rate of 10 percent $^{3}$ that must be paid by patients and collected by medical practitioners in respect of private health services. The same does not apply in respect of government operated or aided hospitals ${ }^{4}$. Besides the 10 percent VAT, patients on Medical Aid Schemes are required to contribute an additional 10 percent of the cost of consultation, and other services such as laboratory services, X-rays 
and other non-invasive examinations like an ultrasound, to mention but a few. VAT doubles the financial contribution for all income groups on Medical Aid. Whereas a person with a higher income may have no difficulty in making an almost 20 percent payment on his account, those with incomes in the lower ranges will experience difficulty to cope with the added expense.

The escalation in costs confines patients to the following options: either to switch over to government health services or to stop treatment altogether. The cumulative effect is a reduction in life expectancy, an increase in the spreading of disease and ultimately a decrease in the number of people who contribute to the tax base.

Furthermore, because the value of these health services is taxed, the service provider must identify and value the taxable services, with the result that the correct application of VAT becomes problematic. In this regard, VAT encourages an imperceptible mitigation of the cost of service by an increase in the cost of drugs that are otherwise exempt from VAT. Further, the exemptions as they relate to drugs, disregard the fundamental issue that it is not the sale of these prescription drugs that constitutes the core business of medical practitioners; it is the service that is fundamental. Experience indicates that, as private health services become expensive and unaffordable, governments adopt the burden of providing such services. This would require increased budgetary allocations, human resource development and expansion of current facilities, which the fiscal may not be in a position to provide ${ }^{5}$.

It is submitted that good health is fundamental for an active and productive life ${ }^{6}$. The right to good health should therefore not be compromised by one's ability or inability to pay for it. Indeed, the right to good health has now been espoused in international documents on human rights. The International Covenant on Economic, Social and Cultural Rights commits signatories, including Botswana, to recognize 'the right to enjoyment of the highest attainable standards of physical and mental health'7. The Universal Declaration states that 'everyone has the right to a standard of living adequate for the health and well-being of himself and his family, including food, clothing, housing and medical care and necessary social services, ${ }^{8}$.

While zero-rating health services ${ }^{9}$ will narrow the tax base and reduce revenue, a good balance between government's economic goals (of raising revenue) and government's social policy (providing health services) must be struck. The government must recognize that without private sector participation in service delivery, government would not be able to achieve some of its objectives. Zerorating medical services will address in one measure the limitations faced by government in providing health services to its citizens. 


\section{THE ROLE OF THE STATE}

The role of government in relation to health-care, involves the combination of the following;

a) A regulator,

b) A funder and

c) A provider.

The regulation of the activities of doctors has been done through delegation to professional bodies ${ }^{10}$. With respect to state hospitals, the government has played a strong funding role. Government through general revenue finances the public health system. User fees of P2.00 for outpatients and P1.00 per day for inpatients are levied. The introduction of VAT now provides an alternative approach to state funding, which is, funding from taxation.

\section{THE MINISTRY OF HEALTH}

The Ministry of Health is responsible for all health matters, including the development, research, administration and implementation of national health policy ${ }^{11}$. Through its various departments the objectives of the ministry include the improvement of the health status of all Botswana citizens by providing quality affordable and accessible preventive, promotive, rehabilitative and curative health services through community and multi-sectoral participation and involvement by the year $2016^{12}$.

\section{PRIVATE SECTOR HEALTH CARE}

Most hospitals and clinics in Botswana are either state-owned or funded, and every citizen has the right to appropriate health treatment almost free of charge. However, people may opt for private health care, which option is expensive. Applying VAT to private health facilities while exempting government facilities imposes a financial penalty in the form of tax on the former. Patients are expected to pay for exercising their right to appropriate treatment in the form of a 10 percent tax on the health services they have received. Medical Aid Schemes, which are a form of insurance, provide an element of cost sharing between the state and the private sector. A patient must be allowed to make a choice as a consumer. VAT constrains the freedom of choice, however, because it increases the cost associated with the exercise of that choice. Ultimately, when private services become too expensive, patients must depend on government facilities. Government's budgetary position may not be able to accommodate 
this increased demand. If experiences in other jurisdictions are considered an indication, any attempt to pursue legal avenues to compel government to provide health services would in all probability fail ${ }^{13}$.

Botswana's medical bill has increased over the number of years ${ }^{14}$. With the HIV-Aids pandemic, the cost will continue to escalate. The high and rising health cost imposes an onerous burden on those who pay, namely; the private sector (businesses providing benefits for their employees), the government or individuals either through direct payment as patients or through private insurance premiums.

The rising cost of health care places a strain on public finance. A great number of people may not have sufficient resources to afford medical insurance or pay for necessary health care. Without private sector participation, government shoulders the entire responsibility. The idea of partnership must be extended to include stakeholders.

To keep the cost of health care low, government must also provide necessary incentives. These would include zero-rating medical facilities in respect of private medical services. Indeed the National Health Policy provides that the development of the private health sector shall be supported and in particular the cooperation of such sector with the public sector shall be encouraged. By comparison, certain jurisdictions have zero-rated basic health services: Australia, Uganda, Namibia and the United Kingdom have zero-rated some health services. The key objective is to ensure for wider access and affordability.

Rising cost also places an enormous financial strain on the private sector, with this cost often being passed to the patient. Further, medical aid organizations may find that their premiums are rising at a rate that deters many individuals from renewing their subscription. This may result in the latter having to curb the rate of increase by restricting the cover available to policyholders.

A reduction in the amounts charged for the provision of medical services is not even an option. Health costs are often pushed up by changes to the prices charged by those who supply the medicines and the technology. There are also other 'suppliers' of health are sources of increasing cost; for instance, medical staff, whose wages and salaries have to be paid. Medical practitioners and medical-aid organizations ae not in a position to influence or contract out of these costs. 


\section{MEDICAL AID MEMBERSHIP STATISTICS IN BOTSWANA}

The following table shows the number of people covered by private medical aid schemes and those who personally incur the cost of health care. The rest of the population depends on government health facilities.

\begin{tabular}{||l|l||}
\hline Country's population 1.7 million & $\begin{array}{l}\text { Number of people covered by } \\
\text { medical aid schemes }\end{array}$ \\
\hline AFA Schemes & 196842 \\
\hline BOMAID & 55330 \\
\hline PRIVATE Patients & 12500 \\
TOTAL & $\mathbf{2 6 4 6 7 2}$ \\
\hline
\end{tabular}

\section{FISCAL POLICY V. SOCIAL POLICY}

Whilst an argument may be made that the primary function of a tax system is to generate revenue needed to finance public administration and the provision of social and economic infrastructure, this function must be balanced with competing social claims. According to the National Development Plan 8, the government's recurrent expenditure on health is expected to slow down and this raises the question of sustainability of the health care system in the long run. Government would, in the long term, be limited to providing only services it can afford. This may impact negatively on the attainment of government's health objectives.

If government is to succeed in its objective of improving the quality of health care services offered in Botswana, it ought to make certain concessions. Also, the vital role and contribution of the private sector should be recognized.

The imposition of VAT on medical services runs contrary to the spirit of vision $2016^{15}$, which espouses a claim that all Batswana must have access to good quality health facilities ${ }^{16}$. Access does not only mean access to government facilities but to private facilities as well. Publicly funded health facilities are funded through taxpayer contributions, whilst private health services are largely funded by private funds. Consequently, private patients should therefore not be required to pay VAT on private services for a state sector they do not use. 


\section{CONCLUSION}

The pursuit of a healthy citizenry requires the active involvement of both the state and the private sector. This requires that the state and the private sector should co-operate in partnership to ensure that the provision of health care is not undermined.

The provision of health care has over the years become costly. While this rise in cost appears to be absorbed by government and the private sector, it is invariably passed on to the patient through an increase in the price of prescription drugs, subscription fees and an increase in the cost of medical services generally. The fact that certain prescribed drugs in the private sector have been exempted from VAT indicates that there is a measure of insight into the negative effect of VAT on the users of private health services. Taxing health expenditures is indeed an area that deserves a careful approach when it comes to the method of taxation. Currently, insurers assume a 90 percent of medical expenses for patients on Medical Aid schemes with the remaining 10 percent being borne by the patient. VAT now makes the individual responsible for almost 20 percent of the account. Better coverage needs to be supplied by Medical Aids. With respect to certain medical aid schemes, for example BPOMAS, this would require a significant increase in contributions from government and government employees. In the case of the other health coverage plans, the clients and their employers would have to provide the extra funds. Employers will need to recover their contributions. To do this they may have to limit the benefits they provide to their employees and in certain instances simply shift the burden of payment to their employees. Zero-rating health services will obviate some of these attendant and glaring problems.

Admittedly good health does not depend purely on direct medical provision. Factors such as income, an unpolluted environment, and a safe lifestyle significantly contribute to the attainment and maintenance of good health.

The imposition of VAT on private medical services fails to recognize the valuable contribution provided by the private sector. While government grapples with different economic and social realities, its solutions and responses to such challenges must be pragmatic. The National Health Policy explicitly states that the government shall, when planning its activities, put health promotion and care and disease prevention among its priorities, the basic objective of which shall be access by all citizens of Botswana to essential health care, whatever their financial resources or place of domicile. In respect of medical services, VAT simply places an excessive burden not only on government but also on people it is intended to assist. 


\section{ENDNOTES}

1 Value Added Tax Act, 2000, Act No 1 of 2001.

2 Act No 1of 1993.

3 Act no 18 of 1992.

3 See section 7 of note 1 supra.

$4 \quad$ See paragraph 1 and 2 of $3^{\text {rd }}$ Schedule.

5 In the United Kingdom the court in $\mathrm{R}$ v Secretary of State for Social Services, Ex parte Hincks (1979) 123 SOL JO 436, held that it was not the function of the court to direct parliament what funds to make available to the health service and how to allocate them. The court could only interfere if the secretary of State acted so as to frustrate the policy of the Act or as no reasonable Minister could have acted. These views were also expressed in $\operatorname{Re} \mathrm{J}$ (a minor) 1992 (4) ALL ER 614 @ 625.

6 Doyal, L \& Gough, I. (1991) A Theory of Human Needs, London, Macmillan, explore the arguments.

7 International Covenant on Economic, (1976) Social and Cultural Rights Article 12.

8 Universal Declaration of Human Rights (1948), Article 25.

9 Countries such as Australia, Namibia, the United Kingdom and Kenya have either zero-rated or exempted the provision of certain health services. Botswana could thus learn from the experiences of these countries.

10 These include the Nurses Association, Dental Association, Private Medical Practitioners Association and the Nurses Council.

11 See the National Health Policy (1995), which was adopted through Presidential Directive CAB 21 (B)/95 dated 20 th July 1995.

12 A more expansive concept of health care would include protection from disease and accidents, protection from adverse environmental factors, the promotion of an environment which would foster improvements in health, and the provision of health care.

13 See $\mathrm{R} v$ Sheffield HA ex parte Seale (1995) 25 BMLR 1 where Auld J articulated the position as follows, "it is not arguable...that the health authority is bound, simply because it has undertaken to provide such a service, to provide it on demand to any individual patient for whom it may work, regardless of financial an other constraints upon the authority.." See also $\underline{\mathrm{R} v}$ Central Birmingham Health Authority, ex parte Collier (1988) unreported, reproduced in part however in Kennedy I and Grubb A; Medical Law-Text with Materials (Butterworths, 1994, $2^{\text {nd }}$ ed.) 428, wherein the court observed as follows, 'difficult and agonizing judgments have to be made as to how a limited budget is best allocated to the maximum advantage of the maximum number of patients. That is not a judgment the court can make'. 
14 In the 2002 Budget Speech, the Ministry of Health was allocated an amount of P380 million and the HIV-Aids project under which all HIVAids activities are consolidated (including the provision of anti-retroviral drugs) being allocated P200 million. It is estimated that as more people die of HIV-Aids, the government budgetary allocations will not be sufficient to meet the demand and constraint placed on governmental health facilities. Thus the position would require an examination of sharing of responsibility for health between private individuals (for their own health and that of others), the state and those who take on responsibility through their status as employers or health professionals.

15 Vision 2016: A Long Term Vision for Botswana adopted in 1997.

16 The vision acknowledges that although Botswana's health infrastructure has improved steadily since independence, well-trained staff does not man many of the clinics and health posts across the country nor are they equipped with adequate equipment. 